\title{
Predictive Validity of Students' Achievement in BECE/JSSCE in Basic Science on Their Achievement in Chemistry in Some Selected States in the Southeast Zone
}

\author{
Nweke Christogonus O. $(\mathrm{PhD})^{1} \quad$ Ogbaga Emmanuel (Ph.D) ${ }^{1} \quad$ Olodu Gabriel O. (Ph.D) ${ }^{2}$ \\ 1.Department of Science Education, Ebonyi State University, Abakaliki, Nigeria \\ 2.Department of Basic Science, Federal College of Education Asaba, Nigeria
}

\begin{abstract}
This study is on the predictive validity of student achievement in Basic Science in the State Ministry of Education Organized Junior Secondary School Certificate Examination on their achievement in chemistry in Senior School Certificate Examination (SSCE) organized by West African Examination Council. The study methodically x-rayed the predictive strength of students' achievement in Basic Science in SMoE - JSSCE on their achievement in Chemistry on SSCE organized by WAEC. To carry out the study, the researchers employed a co relational survey technique as the research design. The sample of the study comprised of 291 students, made up of 134 males and 157 females. These students were drawn from six schools. The selection process involved both purposive and random techniques. Three states in southeast geopolitical zone participated in the study. These States are Ebonyi, Imo and Anambra respectively. Two research questions and two hypotheses guided the study. The hypotheses were tested at 0.05 level of significance. Data were collected from the Students Achievement Records (SAR) of the two examination bodies kept in the schools. Hence the SAR is the instrument for data collection. The data analysis was done using Person Product Moment correlation ( $r$ ) and coefficient of determination $\left(\mathrm{r}^{2}\right)$. Linear regression analysis was further employed in the data, so as to answer the hypotheses. The findings of the study showed that Basic Science in JSSCE organized by State Ministry of Education is a poor predictor of male and female students achievement score in chemistry when they are jointly considered. It also showed that where as basic science in JSSCE is a significant predictor of female students' achievement in chemistry; the reverse is the case for the male students. On the basis of the findings, the researchers recommended that, students, achievement in JSSCE Basic Science should not be used as basis for students' placement in science classes in the senior secondary class. The researchers equally recommended that State Ministry of Education of the study area should recruit and post competent science teachers to both Junior and senior secondary schools. Finally, the researchers equally recommended that the State Ministry of Education of the study area should intensify regular monitoring of schools to ensure teachers' coverage of science curriculum.
\end{abstract}

DOI: $10.7176 / \mathrm{JEP} / 12-36-11$

Publication date: December $31^{\text {st }} 2021$

\section{Introduction}

Basic Science as the first course in the study of science in school is meant to introduce students to the study of science. As a precursor to the learning of science, it is intended to lay the needed foundation for children to understand the nature of the various subjects combined to make up the basic science subject matter. These subjects integrated are: Chemistry, biology and physics (FRN, 2013). By its designation as a core subject in the 9-year basic education programme (FRN, 2013), every student must study and pass it in the BECE/JSSCE in order to be awarded the Basic Education Certificate (FRN: 2013), and to qualify to study in the Senior Secondary School Programme (Adeyemi, 2008).

Chemistry which is a component of basic science has been identified as a very important school subject and its importance in scientific and technological development of any nation has been widely reported (Ademola; Olufunke, and Amoke, 2013). As a subject of study, it has been identified by Ojukuku (2017:1) to be concerned with "understanding the way matter behaves and reacts under different conditions and to device ways in which it can be used to improve our life"

Hence chemistry enables those who studied it to acquire certain scientific skills, such as handling of laboratory apparatus, performing experiment with ease and thinking scientifically (Ojukuku, 2017). Its roles in socioeconomic development of the nations were itemized to include:

- $\quad$ Provision of information on the utilization of natural resources and the creation of artificial ones.

- $\quad$ Provision of knowledge on how matter behaves, and

enhances acquisition of scientific skills (Ojokuku 2017).

Based on these central roles of chemistry in science and the premium that the society places on its study, as a result of the roles it plays, its study is strongly emphasized in the basic science curriculum.

It is on the basis of the contribution of chemistry to the understanding of science and manipulation of scientific principle to the benefit of man that made some researchers refer to it as the core of basic science (Amajioyi, Ene, 
and Udoh, 2017) Indeed, there is no society that is desirous to develop the capacity to harness its natural resources that toys with the study of chemistry (Ademola, etal, 2013).

Hence, chemistry by its nature can be viewed as one of the tripods upon which the study of science rests (Ademola etal 2013). Based on this realization of these crucial roles of chemistry, the Federal Government of Nigeriasince independence made efforts to expose all citizens to the basic knowledge of chemistry. That was the main reason for the integration of most of the topics in chemistry into the basic science curriculum. By this arrangement, every student that completes basic education must have developed the basic skills and awareness in the study of chemistry as a separate subject. It equally gives the basic science learners the necessary head start on the study of chemistry in the senior secondary school. A perusal of the 9-year basic science curriculum gives insight on the chemistry topics contained in the curriculum. Hence a child that completed the 9-year basic education programme must have understood the ease and challenges encountered in the study of chemistry, as he/she have studied at the peripheral level most of the topics in chemistry.

To transit from basic education to the senior secondary school, a terminal/evaluations examination is taken by students. This is the Basic Education Certificate Examination which was formally known as the Junior Secondary School Certificate Examination (JSSCE). The BECE/JSSCE is both a Certificate awarding and a qualifying examination (FRN, 2017).

A minimum of pass in basic science in BECE/JSSCE is considered among other five subjects as qualification to study in senior secondary school. Students' achievements in the various subjects passed in the BECE/JSSCE guide most schools in class placement of the student and subject selection in the senior secondary schools (Faleye and Afolabi, 2005). The same achievement in BECE/JSSCE guides stakeholders in advising students on career choice. This is in line with the initial stipulation of the 6-3-3-4 system of education.

It is perplexing that students' academic achievement records and other science literature such as Ademola etal (2013) contain reports and evidences that contradicts the general expectations that male and female students that performed credibly well in basic science in the JSSCE/BECE do not replicate the same feat in chemistry in their senior secondary school certificate examination. This is further evidenced by reports in students' achievement records in both BECE and SSCE (BECE, 2012, BECE, 2013) BECE, 2014, WAEC, 2015, WAEC, 2016; WAEC, 2017, Faleye and Afolabi, 2005). It is Ironical, that the same student that studied basic science and sat for the BECE/JSSCE and passed it well which qualified her/her to study in senior secondary school, and to develop interest in the study of chemistry is unable to learn chemistry which is an aspect of the subject that make up basic science.

Furthermore, researchers such as Omiwale (2011) and Ademola et al (2013) have lamented on the poor achievement of students in the SSCE chemistry. In Omiwale (2011) account, he noted that on average, students' achievement in chemistry between 2004 and 2006 were $38.8 \%, 50.94 \%$ and $44.9 \%$.

On the basis of this observed lackluster performances Ademola etal (2013) stated that the poor achievement of students in WASSCE in chemistry has continued to be a major concern to all.

It is also alarming as education researchers have revealed that girls have been noted as under achievers in chemistry.(Njoku, 2006). Edokpayi and Suleiman (2011) had reported that girls lag behind on manipulative/reasoning tasks. Such tasks are involved in the study of chemistry. Other researchers that have observed girls' poor achievement in chemistry were Babajide (2011) and Bamigbala (2009). Those reports on poor achievement of girls in chemistry are not in congruence with the same girls' achievement in basic science in the BECE/JSSCE where there was no reported significant difference in the mean achievement scores of male and females (SMoE, 2012; SMoE, 2013; SMoE, 2014). These reports on the contradiction in achievements in the two examinations thereby cast doubt on the predictive validity of achievement in basic science BECE/JSSCE. This erodes stakeholders trust and reliance on the outcome of the examination in taking decisions on their wards' future academic progress.

Predictive validity of a test or examination on the other hand is an important attribute of a test or examination and it is seriously considered in education. It is the basis of forecasting or predicting future achievement of such test takers. The predictor variable (earlier task) is used to forecast the criterion variable (later task). Specifically, the correlation between the predictor variable and the criterion variable is what is called the predictive validity of the test (Abonyi and Ugwuda, 2013).

The validity co-efficient is computed using the two variables (predictor and criterion variables) in order to set up a regression equation. This equation is used in various fields such as education and psychology to make prediction.

This study is aimed at determining the extent to which the JSSCE/BECE in basic science organized by State Ministry of Education predicts students' achievement in chemistry in WASSCE.

The findings of this study will guide education stake holders to determine whether or not to rely on student's achievement in BECE in basic science in taking decision concerning students' future achievement in chemistry.

Specifically, this study was designed to investigate whether there existed differences in the predictive strength of BECE/JSSCE in basic science on male and female students' achievement in chemistry in WASSCE. The study 
also investigated whether achievement in BECE/JSSCE in basic science predicts achievement in the WASSCE chemistry, and the moderating effects of gender on the predictive validity of achievement in BECE/JSSCE in basic science.

\section{Statement of the Problem}

Students' achievement records in BECE/JSSCE in Basic Science and SSCE in Chemistry contain conflicting and contradicting reports. Whereas the BECE/JSSCE records show that students (male and females) pass basic science with high grades, the reverse is the case for the same students in WASSCE in chemistry.

This observed contradiction in the trend of these students' achievement in the two related subjects have made it difficult for stakeholders to take decisions relating to students' future academic achievement in chemistry based on their achievements in BECE/JSSCE in basic science.

Hence, this study was designed to determine the predictive validity of male and female students' achievement in basic science. The study equally sought and determined the moderating effect of gender on the predictive validity of BECE/JSSCE in basic science

\section{Research Questions}

Two research questions guided the study. They were;

1. What is the predictive validity of students' achievement in basic science on their achievement in chemistry in the SSCE?

2. What is the predictive validity of male and female students' achievement in basic science in BECE/JSSCE on their achievement in chemistry in SSCE?

\section{Hypotheses}

Two null hypotheses were used by the researcher to guide the study. The hypotheses were tested at alpha level of 0.05 significance.

$\mathrm{HO}_{1}$. The achievement of students in the JSSCE/BECE does not significantly predict their achievement in chemistry in SSCE

$\mathrm{HO}_{2}$ : The achievement of students in JSSCE/BECE in basic science, does not significantly predict male and female students' achievement in the SSCE in chemistry.

\section{Research Methodology}

The research methodology adopted for the study was correlation survey. 291 students, made up of 134 males and 157 females took part in the study. They were drawn from six (6) schools while two (2) schools each were drawn from each state. The states' sample distributions were, Ebonyi (19 male and 29 females), Imo (84 males and 92 females), and Anambra (35 males and 56 females). The students were made up of BECE/JSSCE candidates of 2012, 2013 and 2014 sets; respectively who passed and wrote chemistry from the sampled schools in the SSCE in the year 2015, 2016 and 2017. These selected students were students from the six sample schools with intact results in both the BECE/JSSCE and SSCE in the two subjects. Students who belong to the sets but had result only in one out of the two examination result records were discarded as invalid. Furthermore, the JSSCE/BECE results of students that did not offer chemistry as a subject were also discarded as invalid.

The samples were selected using a combination of simple random sampling and purposive sampling techniques. Purposive sampling was combined with random sampling because of some criteria outlined, which participating schools must meet to qualify for selection.

The criteria were as follows,

- $\quad$ The school must be presenting candidates for SMoE organized BECE/JSSCE since 2012 to 2014.

- $\quad$ The school must be presenting candidates in the chemistry subjects in SSCE organized by WAEC.

- $\quad$ The school must be presenting candidate in WASSCE between 2015 and 2017.

The school must be co-educational.

The instruments for the data collection were the students' achievement records from the State Ministry of Education organized BECE/JSSCE and that of WAEC organized SSCE. The exact data of interest were extracted from the computer result sheets of the examinations organized by these two examination bodies within the periods. Specifically the BECE/JS SCE computer results sheet used were that of 2014, 2013 and 2012, while the SSCE computer result of interest were that of 20152016 and 2017 respectively:

The grade score that the results were reported were converted to raw scores using the officially obtained grading systems of the two examination bodies. A co-relational analysis was carried out in the paired extracted scores. Pearson Product Moment relation was the tool used in the analysis. The outputs were used to answer the research questions while the output of the linear regression analysis was used to answer the hypotheses. 


\section{Research Question}

Research Question 1

What is the predictive validity of students' achievement on BECE/JSSCE in basic science on their achievement in chemistry in SSCE organized by WAEC?

The summary is presented on table I

TABLE 1: Regression Analysis showing the predictive validity of students' achievement in BECE/JSSCE in basic science and SSCE in chemistry.

\begin{tabular}{lllc}
\hline Computed R & R- Squared R & Standard Error \\
0.11948 & 0.01427 & 0.01065 & 8.71952 \\
\hline
\end{tabular}

From the table 1 , the computed $r$ is 0.011949 , while the adjusted $r^{2}$ is 0.01065 . This means that only $1.1 \%$ of the variations in students' achievement in chemistry that is attributable to their achievement in JSSCE/BECE in Basic science.

This shows a very low but positive relationship between students' achievement in basic science and their achievement in chemistry. Meanwhile the test of hypothesis will further explain whether it is significant.

\section{Research Question 2}

What is the predictive validity of male and female students' achievement in basic science in BECE/JSCCE on their achievement in chemistry in SSCE organized by WAEC?

Data collected from the JSSCE/BECE in basic/science result sheets for male and females and data collected from the SSCE in chemistry achievement result sheets for males and females were analyzed separately using Pearson Products Moment correlation and linear regression. The summary is presented on table 2 for males and on table 3 for the females, respectively.

Table 2: Result of linear regression analysis showing the predictive validity of male students' achievement scores in Basic Science on their achievement scores in SSCE in chemistry.

\begin{tabular}{lllc}
\hline Computed R & R- Squared $\left(\mathrm{R}^{2}\right)$ & Adjusted $\mathrm{R}^{2}$ & Standard Error \\
0.02231 & 0.0050 & 0.00552 & 8.57240 \\
\hline
\end{tabular}

From the table 2 , the computed $\mathrm{r}$ is 0.02231 , and the adjusted $\mathrm{r}^{2}$ is 0.00552 .This shows that approximately $0.6 \%$ of the variations in the male students' achievement in chemistry in the SSCE are explained by their achievement in the basic science in BECE/JSSCE. This is a low predictive strength.

Table 3.

Result of linear regression analysis showing the predictive validity of female students' achievement scores on BECE/JSSCE in basic science on their achievement score in chemistry in SSCE.

The summary is shown on the table.

\begin{tabular}{lllc}
\hline Computed R & R-Squared $\mathrm{r}^{2}$ & Adjusted R & Standard Error \\
0.23621 & 0.05579 & 0.04671 & 8.89539 \\
\hline
\end{tabular}

From the table 3 , the computed $r$ is 0.23621 , while the adjusted $r^{2}$ value is 0.04671 . Hence $4.7 \%$ of the variations in female students' achievement scores in SSCE in chemistry is explained or attributed to their scores in the JSSCE/BECE in basic science. The predictive power is very low. The hypothesis test will further reveal if it is significant

\section{HYPOTHESIS TEST}

$\mathrm{HO}_{1}$ Table 4.Significance of the predictive strength of BECE/JSSCE in basic science on SSCE in Chemistry.

\begin{tabular}{llllll} 
Predictor variable & B & SEB & Beta & T & Sig. of T \\
BECE/Basic Science & 0225436 & 0.057156 & 0.119476 & 3.9389 & 0.0482 \\
Constant & 66.17363 & 3.3 .7833 & & 21.0953 & \\
\hline
\end{tabular}

From the table 4 , the calculated $\mathrm{T}$ value is 3.9389 while the significant $\mathrm{t}$ is 0.0486 . Based on the values displayed, the researchers therefore reject the null hypothesis of no significant predictive strength as the calculated value is greater than the significant $\mathrm{t}$ value. The researcher therefore states that there is a significance difference in the predictive validity of students' achievement in basic science in JSSCE/BECE and their achievement in chemistry in SSCE organized by WAEC.

Hence the regression equation is,

$\mathrm{Y}=66.17365-0.2255435$ (B.S)

Where B.S represents students' achievement score in basic science JSSCE

$\mathrm{Ho}_{2} \quad$ - $\quad$ The achievement of students in the JSSCE/BECE in basic science does not significantly predict male and female students' achievement scores in the SSCE in chemistry.

To test the hypothesis, the predictive strength of BECE/JSSCE in basic science obtained for males and females in SSCE in chemistry were subjected to a test of significant at $95 \%$ confidence level. The summary of the results are presented on table 5 for the males and Table 6 for the females. 


\begin{tabular}{llllll}
\hline Predictor variable & B & SEB & Beta & T & Sig. of T \\
BECE/Basic Science & -0.024285 & 0.08445 & 0.022313 & 0.08269 & 0.774 \\
Constant & 61.24573 & 4.505325 & & 13.5940 & \\
\hline$P<0.05$ & & &
\end{tabular}
$\mathrm{P}<0.05$

From the result displayed on table 5 , the calculated $t$ value of 0.08269 is less than the significant table $t$-value of 0.7740 at 0.05 significant levels, or $95 \%$ confident level. Based on the results, the researcher therefore upholds the null hypothesis which states that the achievement of male students in the JSSCE/BECE in basic science does not significantly predict their achievement in SSCE in chemistry. Hence the regression equation is $Y=61.24573-$ 0.0242 (B.S) where B.S is the students' score in basic science in the JSSCE/BECE.

Table 6 predictive strength of female students achievement score in JSSCE / BECE in basic science on their achievement score in chemistry.

\begin{tabular}{llllll}
\hline Predictor variable & B & SEB & Beta & t & Sig. of T \\
BECE/Basic Science & -0.200074 & 0.0807011 & -0.236205 & 2.4790 & 0.0148 \\
Constant & 71.39837 & 4.618681 & & 15.4581 & \\
\hline
\end{tabular}
$\mathrm{P}<0.05$

Based on the result of data analysis presented on table 6 , the calculated t value is 2.4790 while the significance $t$ is 0.0148 . This shows that for females the calculated $t$ is greater than the $t$ critical value. As this is the case, the researcher therefore drops the null hypothesis of no predictive significant difference.

The researcher therefore concludes that the female students achievement in the BECE/JSSCE in basic science significantly predict their students' achievement in chemistry, the associated regression equation therefore is $\mathrm{Y}=$ $71.39837-0.200074$ (B.S), where B.S is the students achievement in the JSSCE/BECE by the student

\section{Discussions}

The study shows that the achievement score of student in basic science in BECE significantly predicts students' achievement score in chemistry in SSCE.

Although the predictive power of basic science in BECE/JSSCE in predicting achievement scores in chemistry is low, but that notwithstanding, the test of significance showed that the observed variations were not by mere chance.

This finding is consistent with Edokpayi and Suleiman (2011), and Adebayo (2002) findings which stated that there exists a poor but significant relationship between students' achievement in integrated science in the JSSCE and their later achievement in chemistry in the SSCE. The findings of this study do not conform to the findings made by Adeyemi (2008), as he reported that integrated science is a strong predictor of students' achievement in the later science subjects in SSCE.

The findings are in agreement with Faleye and Afolabi (2005) as they had reported that students' academic performance in JSSCE (BECE) tends to have a low capacity to predict students' achievement in science subject in SSCE.

Finally, the finding of this study disagrees with those of Osokoya (1999), Olaoye and Afuwape (2004) which reported that integrated science is a good predictor of achievement in chemistry at SSCE.

However, as the findings of this study showed that male students' achievement score in basic science has no predictive validity on their achievement scores in chemistry, the reverse is the case for female student's achievement scores in basic science. The finding therefore contradicts Edokpayi and Suleiman) (2011) report, which stated that there is a positive and significant relationship between male students' achievement scores in basic science JSSCE and their achievement scores in SSCE in chemistry organized by NECO.

The findings agree with that of Alonge (1990) and Oluwole (2003). These researchers held that gender is a significant moderator variable on the ability of JSSCE to predict achievement scores in SSCE. The findings further disagreed with Olaoye and Afuwape (2004) assertion that there was no significant difference between male and female students' achievement in chemistry.

\section{Conclusion and Recommendation}

The findings of this study have revealed very interesting discoveries. These are:

That basic science predicts achievement for male and female students when their performances are jointly considered.

Whereas basic science predicts the female students' achievement score in chemistry, it is unable to do the same for the male students.

Based on these findings, female students do better than male students when their performances are considered in the two terminal but related examinations. The implication is that the study of chemistry should not be seen as a male enterprise alone. It is therefore important that stakeholders in education should take the findings of this study seriously and desist from giving the study of science subjects especially chemistry a Masculine outlook. 


\section{REFERENCES}

Abonyi, O.S; and Ugwuda, S.O. (2013) Predictive Validity of NECO Junior Secondary School Certificate Examination on Students' Achievement in NECO Senior Secondary Certificate (NECO SSCE). Research gate. http//www.research gate.net/ Publication 1259761311.

Adeyemi, T.O., (2008).Predicting Students' Performance is Senior Secondary Certificate Examination from Performance In Junior Secondary Certificate Examination in Ondo State. Nigeria. Humanity and Social Science Journal 3. (10).

Anambra State Ministry of Education (2014) Basic Education Certificate Examination Result. Awka. Examination Development.

Anambra State Ministry of Education. (2012). Basic Education Certificate Examination Result. Awka. Examination Development Centre.

Anambra State Ministry of Education. (2013). Basic Education Certificate Examination Result Awka. Examination Development Centre.

Babajide, V.T.F., (2010). A Generative and Predict-Observe -Explain Instructional Strategies as Determinate of Senior Secondary School Students' Achievement and Practical Skills in Physics. Unpublished PhD Desertation University of Ibadan.

Bamigbala, P.A., (2006). Towards the Improvement of Teaching and Learning of Integrated Science in Nigeria Colleges of Education. A Case Study of Osun State College of Education, Ila - Orangun. Oro Science Journal 4(694): 156-161.

Ebonyi State Ministry of Education (2013). Basic Education Certificate Examination, Abakaliki, Examination Development Center

Ebonyi State Ministry of Education (SMoE) (2012) Basic Education (SMoE), (2013) Basic Education Certificate Examination (BECE) 2013 Result. Abakaliki, Examination Development Centre.

Ebonyi, State Ministry of Education (SMoE). (2014). Basic Education Certificate Examination. Result. Abakaliki. Examination Development Centre,

Enugu State Ministry of Education (2019). Analysis of 2012-2015 Basic Education Certificate Examination Results. Enugu. Examination Development Centre.

Falaye, B.A., and Afolabi, E.R.I. (2005). Predictiv Validity of Osun State Junior Secondary School Certificate Examinations. Electronics Journal of Research in Educational Psychology 5(1), 13FUN.

Federal Republic of Nigeria (1986). National Policy on Science and Technology Abuja. NERDC).

Federal Republic of Nigeria (2013). National Policy on Education $6^{\text {th }}$ Edition NERDC, 3 Jibown Street Yaba, Lagos-Nigeria.

Imo State Ministry of Education (2013). Basic Education Certificate Examination Result. Owerri. Examination Development Centre.

Imo State Ministry of Education (2014). Basic Education Certificate Examination Result.Owerri. Examination Development Centre

Imo State Ministry of Education. (2012). Basic Education Certificate Examination. Owerri Examination Development Center.

Nigerian Education Research Development centre (NERDC). (2008). Public Examination as Predictor of University Students Academic Achievement Zero Draft Research Report. Abuja - Nigeria. NERDC.

Nigerian Education Research Development Centre (NERDC). (2012). National Policy on Science Technology and Innovation. In News African: Federal Government Approves new Policy in science Technology and Innovation Feb. 12, 2012.

Njoku, 2.C; (2006). Girls Disadvantages in Science and Technology: Possible Explanations for Gender Differences in Pupils' Achievements and Interest in Basic Education. International Journal of Educational Research. Research Vol. 17 No 12006.

Nwankwo M.N., and Madu, B.C. (2014) Effect of Analogy Teaching Approach on Students' Conceptual charge in Physics. Greener Journal of educational research 4 (4); 119-125. http//dx.org/10.15580/Gjea 2014.4032416.

Ojukuku G, C.(2017). Understanding Chemistry For Schools and Colleges. Second Reversed Edition. Zaria, Presson Chembook.

Olatoye, R.A., and Afuwape, M.O. (2004) Students' Integrated Science Achievement as a Predictor of Later Achievement in Biology, Chemistry and Physics. Journal of Science Teachers Association of Nigeria (STAN).

Omiwale, B.J., (2011). Relationship Between Problem Solving Ability and Achievement in Physics Among Senior Secondary School Students in Osun State Nigeria. African Symposium. An Online Journal of The African Educational Research Network. ISSBN. TX 6-342 - 323.

Osokoya. (1999). Predictive Validity of Integrated Science JSSCE. In N.I. Dike and M.A. Garba (eds). Students integrated science Achievement as Predictor of Later Achievement in Biology in Selected Government secondary schools in Soba Local Government Area, Kaduna State Journal of Research and method, in 
Education

West African Examination Council (WAEC). (2010) Senior Secondary School Certificate Examination Result. Yaba-Lagos.

West African Examination Council (WAEC). (2015) Senior Secondary School Certificate Examination Result. Yaba-Lagos.

West African Examination Council (WAEC). (2017) Senior Secondary Schools Certificate Examination Result. Yaba-Lagos.

West African Examination Council, (WA). (2016) Senior Secondary School Certificate Examination Result. YabaLagos. 